\title{
RESEARCH
}

Open Access

\section{Covid-19 in Israel: socio-demographic characteristics of first wave morbidity in Jewish and Arab communities}

\author{
Daphna Birenbaum-Carmeli ${ }^{*}$ (D) and Judith Chassida ${ }^{2}$
}

\begin{abstract}
Background: The first wave of the Covid-19 pandemic hit Israel in late February 2020. The present study examines patterns of the first wave of Covid-19 morbidity in Israel at the macro level, during the period of late February to early June 2020, when the first wave has faded out. The analysis focuses on the significance of four sociodemographic variables: socioeconomic status, population density, rate of elderly population and minority status (Jewish / Arab identity) of the population in cities with 5000 residents or more. Additionally, we take a closer look into the association between morbidity rates and one SES component - home Internet access.

Methods: The article is a cross sectional study of morbidity rates, investigated on a residential community basis. Following the descriptive statistics, we move on to present multivariate analysis to explore associations between these variables and Covid-19 morbidity in Israel.

Results: Both the descriptive statistics and regressions show morbidity rates to be positively associated with population density. Socioeconomic status as well as the size of elderly population were both significantly related to morbidity, but only in Jewish communities. Interestingly, the association was inverse in both cases. i.e., the higher the SES the lower the morbidity and the larger the elderly population, the lower the community's morbidity. Another interesting result is that overall, morbidity rates in Jewish cities were consistently higher than in Arab communities.

Conclusions: We attribute the low morbidity rates in communities with relatively small elderly populations to the exceptionally high fertility rates in ultra-orthodox communities that sustained increased rates of morbidity; the lower morbidity in Arab communities is attributed to several factors, including the spatial Jewish-Arab segregation.
\end{abstract}

Keywords: Covid-19, Morbidity rate, Israel, Socioeconomic status, Population density, Elderly population, Internet access, Minority, Jewish, Arab

\footnotetext{
* Correspondence: daphna@research.haifa.ac.il

${ }^{1}$ Faculty of Social Welfare and Health Sciences, University of Haifa, Haifa,

Israel

Full list of author information is available at the end of the article
}

(c) The Author(s). 2020 Open Access This article is licensed under a Creative Commons Attribution 4.0 International License, which permits use, sharing, adaptation, distribution and reproduction in any medium or format, as long as you give appropriate credit to the original author(s) and the source, provide a link to the Creative Commons licence, and indicate if changes were made. The images or other third party material in this article are included in the article's Creative Commons licence, unless indicated otherwise in a credit line to the material. If material is not included in the article's Creative Commons licence and your intended use is not permitted by statutory regulation or exceeds the permitted use, you will need to obtain permission directly from the copyright holder. To view a copy of this licence, visit http://creativecommons.org/licenses/by/4.0/. The Creative Commons Public Domain Dedication waiver (http://creativecommons.org/publicdomain/zero/1.0/) applies to the data made available in this article, unless otherwise stated in a credit line to the data. 


\section{Introduction}

Israel's first case of Covid-19 was diagnosed on February 26, 2020. On March 14, 2020, 200 cases were confirmed and additional 40-60 cases were being diagnosed daily. Two days later, on March 16, a general lockdown was declared. Mask wearing in public became obligatory on April 12th, but the requirement was hardly enforced for long weeks thereafter. Professionals offered polarized forecasts, ranging from a total of 10 deaths throughout the epidemic, to ten thousand deaths, accompanied by fatal shortage of ICU facilities, ventilators and medical staff. The first wave climaxed in early April with nearly 10,000 active cases and 500-700 additional confirmed cases a day. Since then, the spread started to slow down. Starting April 19, lockdown restrictions were gradually relaxed. As of early June 2020, Israel had roughly 2000 active cases, less than 300 deaths and a fatality rate of $1.67 \%$, substantially lower than that of most West European countries and well below the world average of $6.15 \% .{ }^{1}$ At the time of this writing, a second wave of Covid-19 is plaguing Israel. The present study explores morbidity rates in Israel on a residential community basis, aiming to identify associations with main sociodemographic variables, as they evolved under the lockdown practice.

Scholars have suggested numerous variables that may affect the spread and scope of the pandemic, including medical resources, health coverage, life expectancy, employment rates, income inequality, levels of social connectedness and education, alongside religious affiliation, household size, population age composition, population density and ecological footprint [1]. Of this wide array, the present study focuses on four variables that have been repeatedly suggested in Israel's public discourse, as influencing local morbidity rates: population density, socioeconomic status (SES), percentage of elderly population and minority status. We supplement these four variables by zooming in on one component of the SES index, that of household internet access, which was pointed out as associated with morbidity in Israel, due to inter-sector differences in access. We start with descriptive statistics of these variables. To the best of our knowledge, despite repeated references in the media and public discourse, no systematic analysis of these variables has been conducted to date. A subsequent multivariate analysis seeks to explain the associations between these variables and morbidity rates.

Socioeconomic status has often been mentioned in conjunction with rates of Covid-19 morbidity. In the UK, for instance, the disease appears to have spread along class lines. In the early stages of the outbreak, regions with higher SES were over-represented among the sick. Explanations attributed the excess to more frequent traveling and social contacts, alongside better access to testing [2]. Later on, however, infection rates started to rise in densely populated areas, especially those suffering higher levels of deprivation, affecting primarily people from lower socioeconomic urban areas, many of whom also belonged to ethnic minorities [3]. A similar picture emerged in New York City, where lowincome neighborhoods were disproportionately hit by the pandemic [4] The contribution of SES to morbidity rates is thought to operate through various channels of disadvantage, such as posing hurdles to social distancing due to crowded housing, jobs that require physical presence and reliance on public transport for job attendance. $^{2}$

Population density is another factor that has long been connected to epidemics. In the present pandemic, high morbidity was documented in dense European and American metropolises like London [3], Paris [5], Milan (https://www.citypopulation.de/en/italy/covid/) and New York [6]. All these cities stood out in comparison to their less heavily populated surroundings, with substantially elevated rates of morbidity. Population density is, however, not the sole determinant of morbidity rates, as powerfully demonstrated by the low incidence of disease in Asian megacities like Hong Kong, Singapore, Seoul and Tokyo.

Age composition has been singled out in the present pandemic, as associated with morbidity rates [7]. High mortality was attributed to the presence of numerous elderly people, defining such age structure as creating vulnerability to Covid-19 and especially, to its complications. Social settings in which multi-generation households are prevalent have also been mentioned as more susceptible to contagion and subsequent death, primarily among older people [8].

Minority status is yet another factor suggested as associated with increased morbidity. In England, for instance, a high proportion of black and minority residents was found to be the strongest predictor of high Covid-19 death rate and people of ethnic minority descent were overrepresented among Covid-19 victims [9]. Evidence in the same direction came from the U.S., where black and indigenous people sustained twice or more Covid-19 deaths per capita as compared to white Americans [10].

In the following, we explore the extent to which these factors - SES, population density, size of elderly population and minority status - were associated with morbidity rates in Israel's residential communities.

\footnotetext{
${ }^{2}$ http://info.primarycare.hms.harvard.edu/blog/social-conditions-shapecovid

${ }^{1}$ https://ourworldindata.org/mortality-risk-covid; identical to extrapolations from https://www.worldometers.info/coronavirus/, on May 28, 2020. 


\section{The research field}

Israel's population currently includes over 9 million people, roughly three quarters of whom are Jewish, $21 \%$ Arabs and $5 \%$ family members of Jewish immigrants or persons of Jewish descent who were not recognized by the state as Jewish. The population is almost entirely (97.6\%) literate and its life expectancy is 82.5 years [11], among the world's highest. Israel is highly urban, though its largest cities, Jerusalem and Tel Aviv, count roughly a million and half a million residents respectively. The population density is, however, extremely high, exceeding 410 people per square kilometer, ranking among the densest OECD countries. (The respective figures in the UK, Spain and the USA are 275, 93 and 26.). Israel's population has been consistently growing since the establishment of the state, due to immigration and an exceptional fertility rate: 3.17 children per Jewish woman and 3.04 per Arab woman [12]. Notable within these overall figures is the Jewish ultra-orthodox subpopulation, which accounts for some $12 \%$ of the country's population, residing in segregated communities. Women's fertility rate in these communities is 7.1 children per woman and [13].

Arab citizens comprise an ethnic national minority in Israel. Despite formal equality, Arabs in Israel suffer various forms of socioeconomic discrimination and disadvantage. Similar to findings from other settings (e.g., $[14,15]$ ), in Israel, too, the health status of Arab citizens is inferior to that of the Jewish majority, manifesting, among other things, higher infant mortality and shorter life expectancy [12]. The differences are attributed mainly to higher rates of congenital disorders, road accidents and smoking. Later on in life, chronic diseases, especially diabetes and obesity are more prevalent. Structural disparities exert great influence as well, as evident in gaps in access to healthcare, health promotion initiatives and disease detection [16]. Arab communities are highly segregated and even in the nine mixed cities, Jews and Arabs live in separate streets and neighborhoods [17]. Though educational accomplishments of Arab men and women in Israel have risen greatly, the percentage of high school graduates who can be admitted to higher education is lower in the Arab sector than among Jewish Israelis and the rate of university graduates is roughly half as high [18]. The distribution of communities by SES attests to the extreme disparities: Arab localities comprise $82 \%$ of the residential communities in the lowest SES rank (1), 80\% in the second (2) and 75\% in the third (3), but not a single Arab community is included in the top SES ranks of 7-10 [16]. Israel's Arab population is relatively young, showing a median age of 22 , vs. 31 in the Jewish population. The average ages are 26.24 and 34.00 respectively [16].

Against this backdrop and the local discourse about the association between Covid-19 morbidity and the four scrutinized variables, we set off to explore the actual findings.

\section{Materials and methods}

This is a cross-sectional study, investigating all of Israel's residential communities with more than 5000 people (i.e., full population rather than sample). It focuses on Israel's cumulative Covid-19 morbidity figures since the beginning of national registration in February 23, 2020, up until June 2, 2020, when the first wave of the epidemic was considered to have been contained.

\section{Data source}

Data was retrieved from the official publication of Clalit Health Services, Israel's largest HMO, which presented daily updates of Ministry of Health cumulative morbidity figures, by residential community. (The dataset is available in https://www.clalit.co.il/he/your_health/family/ Documents/city3105.pdf.) The data includes approximately 197 municipalities in Israel.

To supplement this data, we retrieved, for each community, several figures from Israel's Central Bureau of Statistics' publications. The added figures included:

1. Population density in every community, calculated as the number of residents divided by the community's area of jurisdiction. As such, this is a continuous variable. ${ }^{3}$

2. The communities' SES, on a 1-10 (the highest) scale as defined by Israel's Central Bureau of Statistics. This is calculated as continuous variable. ${ }^{4}$

3. Proportion of local population aged $65+$, thereafter called 'elderly population', calculated as the number of $65+$ local residents divided by the community's total population. This is a continuous variable. ${ }^{5}$

4. Ethnic Nationality as a dichotomous variable, defining 'Jewish' and 'Arab' communities. This is a dichotomous variable.

The dependent variable was the number of confirmed Covid-19 cases in each community in June 2, 2020, and their rate per thousand residents. This continuous variable may be challenged as it heavily depends on the testing policy at any given day. While acknowledging this limitation, we nonetheless consider the official morbidity rate a foundational indicator of local disease spread for several reasons. Morbidity rate was a major component in official assessments of the local spread of the epidemic and as such, was formative of related state policy. This centrality was enhanced by a report, published at the height of the epidemic first wave by the influential Advisory Team to the Center for National Security, that

\footnotetext{
${ }^{3}$ https://www.cbs.gov.il/he/pages/default.aspx

${ }^{4}$ https://www.cbs.gov.il/he/publications/doclib/1999/local_authorities/ pdf/t02.pdf

${ }^{5}$ https://data.gov.il/dataset/residents_in_israel_by_communities_and_ age_groups/resource/64edd0ee-3d5d-43ce-8562-c336c24dbc1f
} 
contended, on the basis of emerging local and global evidence, that the number of asymptomatically ill persons was not very large. In light of this clinical and policy shaping significance, we consider the Ministry of Health's daily morbidity figures a valuable indicator for tracking the spread of Coronavirus in Israel.

\section{Data processing}

Data is presented in two stages. First, descriptive statistics outline the distribution of the research variables and the average figures. In the second section, a multivariate analysis is carried out, in order to assess the association between each variable and a community's Covid-19 morbidity. The regression data is then used to estimate the 'marginal effect' of each of the study's variables on local morbidity rates.

\section{Results}

Looking at Israel's morbidity rates by SES (Fig. 1), we observe a general trend, suggesting that a rise in SES is associated with a decrease in morbidity rates, i.e., higher morbidity in lower ranking communities and lower morbidity in wealthier ones.

Notably, the SES levels 2 and 3 sustained the highest morbidity rates in Israel. These categories include numerous Jewish orthodox communities (e.g. Bnei Brak, Elad, Kiryat Yearim, Emanuel, Rechasim in rank 2 and Beit Shemesh, and Zefat in rank 3), which have indeed suffered the highest morbidity in the country. SES level 1 is also populated by orthodox communities. However, it also includes numerous peripheral Arab Bedouin communities. These communities were relatively less affected than communities in the two subsequent levels, as illustrated in Fig. 1. SES category 4 does not include as many orthodox communities, but rather traditional peripheral Jewish as well as Arab settlements. These communities have apparently been relatively less affected than their poorer and wealthier counterparts, possibly due to their peripheral location and distance from major sites of contagion.

When assessed by the communities' population density (Fig. 2), the morbidity distribution appears to follow an even clearer trend, generally increasing with the population density: the higher the density, the higher the morbidity. At the upper right hand corner, the city of Bnei Brak, with the highest population density in Israel - roughly $50 \%$ denser than the subsequent town (See Table 1) - sustained the highest morbidity rate in Israel during the epidemic's first wave: 14.72 per 1000 persons. At the upper left corner, the small Arab community of Deer El Assad is an outlier, where morbidity soared for a relatively short period of time in April, but was contained within a few days.

Nonetheless, as suggested by Table 1, communities differed greatly. For example, though Elad's population density is roughly $3 / 4$ that of Givataim, morbidity rate in the former was 10 times that of the latter. Visibly, orthodox cities suffered much greater morbidity than denser non-orthodox communities. Morbidity rates thus increased with population density. Yet, it was clearly not a sole determining factor.

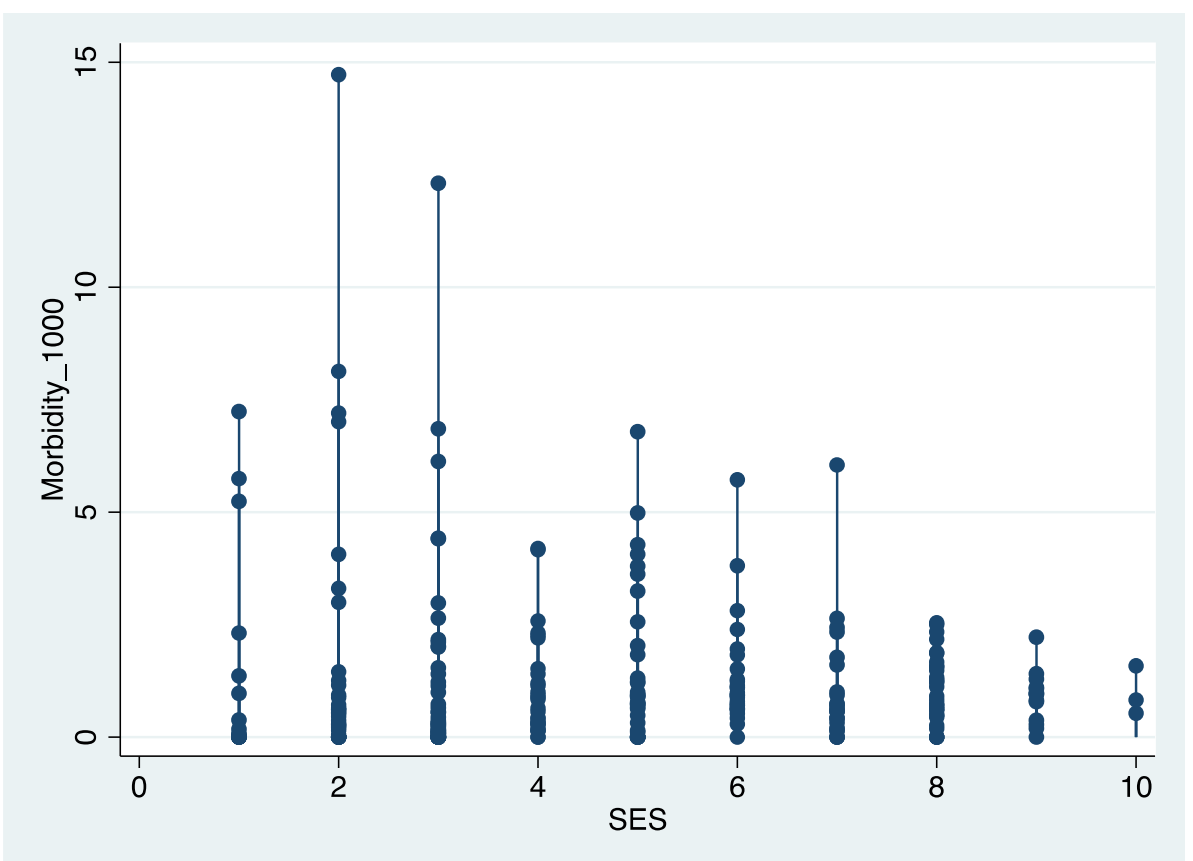

Fig. 1 Confirmed morbidity by SES 


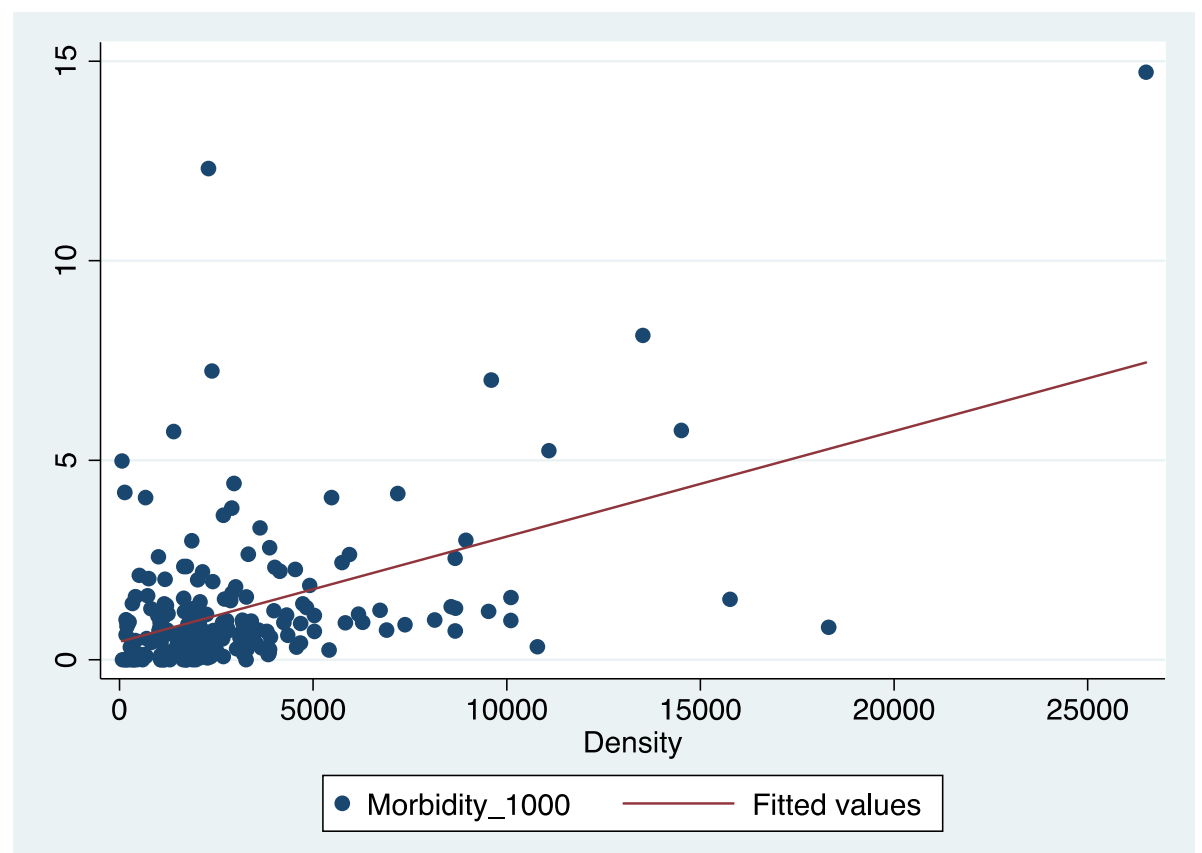

Fig. 2 Morbidity Rates by Community Population Density

The third factor is the size of elderly population as measured by the proportion of people aged $65+$ in the community. The distribution (Fig. 3) depicted an inverse relation between the variables, i.e., the higher the percentage of elderly persons in a community, the lower the morbidity. The two outliers are once again, the communities of Bnei Brak and Deer El Assad, which stood out in the density distribution above (Fig. 2).

The descrpetive statisitics thus suggest 1 . Inverse association between a community's SES and its morbidity rate; 2. Positive association between population density and morbidity; 3 . Inverse relation between percentage of elderly population and morbidity.

Table 1 Covid-19 morbidity rates in Israel's densest communities

\begin{tabular}{lll}
\hline Community & Population density (pop/ $\mathrm{km}^{2)}$ & Morbidity (per 1000) \\
\hline Bnei Brak $(\mathrm{O})^{\mathrm{a}}$ & 26,508 & 14.72 \\
Givataim & 17,589 & 0.81 \\
Bat Yam & 15,651 & 1.51 \\
Modi'in Ilit (O) & 12,953 & 5.74 \\
Elad (O) & 13,515 & 8.12 \\
Kiriat Motzkin & 10,323 & 0.32 \\
Holon & 9882 & 0.98 \\
Givat Shmuel & 9735 & 1.56 \\
Beitar llit (O) & 9702 & 5.23 \\
Ramt Gan & 9190 & 1.21 \\
\hline
\end{tabular}

${ }^{\mathrm{a}}$ Designating an orthodox Jewish community
The last result, which goes somewhat against findings reported from other settings, requires some more attention. We start with the city of Bnei Brak, that had the highest morbidity rate in Israel (14.7 per 1000) but a mere $8.9 \%$ of elderly residents. Jerusalem and Haifa, in contrast, with evidently larger proportions of elderly residents (12.3 and 27\% respectively), had strikingly lower morbidity rates: 4.16 and 0.61 per 1000 respectively. A more systematic look into the communities with the highest morbidity rates (Table 2 ), shows that the proportions of elderly population in these communities were all below the average for the Jewish sector (13\%) and even below the national average (11\%), thereby illustrating the inverse association:

Notably, all four cities are orthodox Jewish communities.

Exploring the opposite direction, reveals similar findings. As shown in Table 3, the morbidity rates in Israel's 'oldest communities', namely those with the largest proportions of people older than 65 (19-21\%), were consistently below $(0.32-1.51)$ the national average of 1.64 per 1000 at the time (June 2, 2020). None of these communities is orthodox.

At a glance, the low proportion of elderly people in Israel might be taken as a protective factor that helped moderate morbidity rates in the country. However, the findings suggest the opposite, as illustrated in Tables 2 and 3. The key factor explaining this unusual distribution is the exceptional fertility rates in Israel's orthodox Jewish communities that stand on 7.1 children per woman, as opposed to roughly 3 


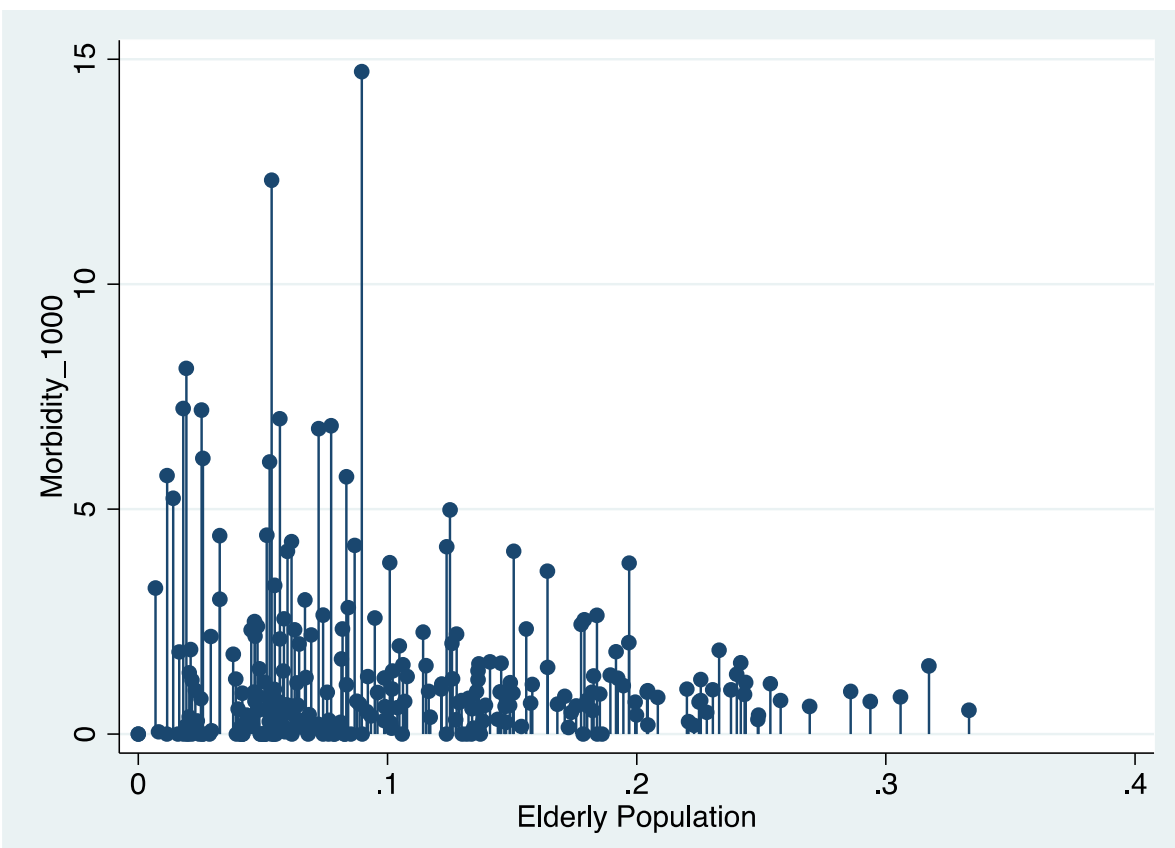

Fig. 3 Morbidity rate by number of residents aged 65+

children per woman in other Jewish and Arab communities. This difference drastically reduces the percentage of the orthodox communities' elderly cohorts. At the same time, these very large families are mostly poor, often crowding in small apartments, and as such, are prone to contagion.

In order to gain a closer insight into the association of each variable with morbidity rates, we conducted a linear regression, wherein the dependent variable is the morbidity rate. The following results were obtained (Table 4):

The regression model thus predicts $38.1 \%\left(R^{2}=0.381\right)$ of the inter-community morbidity rate variance in Israel at the community level, by SES, density, elderly population and minority status. As shown, SES turned out to be statistically insignificant, but population density, size of elderly population and minority status emerged as significantly associated with morbidity rates. The association of each variable with COVID-19 communities' morbidity rates is presented in Fig. 4, which shows the respective regression lines.

Table 2 Towns with the highest morbidity rates by percent of elderly population

\begin{tabular}{lll}
\hline Town & Morbidity rate (per 1000) & \% of population aged 65+ \\
\hline Bnei Brak & 14.70 & 8.9 \\
Elad & 8.12 & 1.9 \\
Kiryat Ye'earim & 7.00 & 5.6 \\
Efrat & 5.71 & 8.3 \\
\hline
\end{tabular}

The nearly horizontal SES line visualizes the lack of statistically significant association between this variable and the rate of morbidity in Israel. Population density, in contradistinction, emerged as significant, affirming the public discourse that linked crowdedness with increased morbidity. Indeed, population density emerged as the strongest association with communities' morbidity rates $(\beta=0.439)$. A 100 person increase per $\mathrm{km}^{2}$, raises morbidity by 0.024 patients per thousand $(b=0.00024)$, namely, 2.4 additional patients per 100,000 persons. As for the percentage of a community's elderly residents, as suggested by the descriptive statistics, the regression shows a significant inverse association between this variable and communities' morbidity rates, i.e., the smaller the elderly population, the higher the local rate of morbidity $(b=-9.16)$. In terms of minority status, despite their lower SES and minority status, Arab communities sustained lower morbidity rates, i.e., Jewish communities suffered 1.68 higher morbidity rates compared to Arab communities $(b=1.68, \beta=0.437)$. Moreover, the JewishArab gap in morbidity proved persistent. Figures 5 and 6 present the marginal association of population density and percent of elderly population - the two variables that were found to be statistically significant - with morbidity rates in the Jewish and Arab populations.

The calculation is based on the regression model, assuming that all other variables are held constant. The figures demonstrate that the higher the population density, the higher the community's morbidity rates and the larger the elderly population, the lower the morbidity 
Table 3 Communities with the highest percentage of populate aged 65+

\begin{tabular}{llll}
\hline Town & \% of population aged 65+ & Morbidity rate (per 1,000) & SES \\
\hline Bat Yam & 21 & 1.51 & 6 \\
Kiryat Yam & 21 & 0.72 & 5 \\
Kiriat Motskin & 20 & 0.32 & 7 \\
Hifa & 20 & 0.61 & 7 \\
Kiriat Bialik & 19 & 0.41 & 7 \\
\hline
\end{tabular}

Source: Joint-Israel. 2018. People aged $65+$ in Israel.

https://brookdale.jdc.org.il/wp-content/uploads/2018/02/MJB-Facts_and_Figures_Elderly-65_in_Israel-2018_Hebrew.pdf

rate. Equally important: at any given value of population density or size of elderly population, the gap in morbidity rate between the Jewish and Arab cities persists, with morbidity rates consistently lower in Arab communities.

In the light of the emergent gap in morbidity between Arab and Jewish communities, we divided our calculation and produced the average values of the scrutinized sociodemographic variables alongside Covid-19 morbidity rates in Jewish vs. Arab communities. Table 5 presents the averge values in each sector.

The table reveals a clear Jewish-Arab difference: with communities twice or more richer, denser and older, Israel's Jewish cities sustained 2.6 times the morbidity of their Arab counterparts. Whereas these figures accord with international findings regarding population density and proportion of elderly residents, the higher morbidity in richer cities is exceptional. In other words, Israel's Arab communities, despite being much poorer and despite belonging to an underprivileged minority, sustained less than half the morbidity of their wealthier Jewish neighbors. Therefore, we examined how these variables are associated with morbidity in Jewish vs. Arab communities. The linear regression analysis presented in Table 6 , reveals further details and differences:

The analysis shows that when considered on its own, SES (Model 1) becomes significant in the Jewish communities though not in the Arab ones. Thus, in Israel's Jewish communities SES was associated with morbidity in a manner similar to that observed elsewhere, i.e., poorer communities were more vulnerable to the virus than wealthier ones. More concretely, a rise in one SES rank in a Jewish community was associated with a reduction of

Table 4 Linear regression to estimate the association of SES, population density, size of elderly population and ethnicity on morbidity in Israel

\begin{tabular}{lll}
\hline Variables & coef. (se) & $\boldsymbol{\beta}$ \\
\hline SES & $-0.122(0.07)$ & -0.150 \\
Density & $0.00024^{*}(0.00)$ & 0.439 \\
Age 65+ & $-9.16^{*}(2.28)$ & -0.343 \\
Jewish / Arab & $1.682^{*}(0.39)$ & 0.437 \\
$\mathrm{R}^{2}$ & 0.381 & \\
$\mathrm{~N}$ & 197 & \\
\hline
\end{tabular}

0.373 sick person per 1000. In the Arab sector, no such association was found. However, once the other variables are added (Model 2), the association of SES with morbidity once again becomes statistically insignificant also in the Jewish sector. Population density (Model 2), however, proved significant and equally influential in both sectors.

The third variable, proportion of elderly population, also emerged as statistically insignificant in the Arab communities but significant and inversely associated with morbidity in Jewish communities, i.e., a smaller elderly population was associated with higher morbidity. Another substantial inter-sectorial difference related to the explained variance. While explaining nearly $38 \%$ of the variance in morbidity rates in Jewish communities, Model 2 accounts for less than 11\% in Arab settlements. The model thus reaffirmed the lay perception that population density was positively associated with morbidity rates. However, in contrast to international findings, SES was statistically insignificant to morbidity rates in the Arab communities and even in the Jewish sector, the association was weak.

Finally, some Israeli commentators attributed the high morbidity rates in some ultra-orthodox communities to the scarcity of home and mobile Internet access in these communities, that wish to maintain but minimal contact with their non-orthodox surrounding. ('Kosher mobile phones' have only pre-designated internet access, e.g., to banks, HMO etc.) This virtual detachment was assumed to underlie the communities' lack of awareness and belated application of the protective measures and lockdown guidelines. We therefore zoomed in on this specific component of the SES index and conducted a specific linear regression.

The general regression revealed no association with internet access. Sector specific analyses (Table 7) found that home Internet access followed the SES pattern, namely, significant association with morbidity only in Jewish communities and only when considered on its own.

However, the latter association was substantial: a 10\% increase in home internet access in Jewish communities was associated with a morbidity decline of 0.3 person per 1000. The resemblance to SES patterns is reasonable, given the fact that internet access is a component of the SES index. 

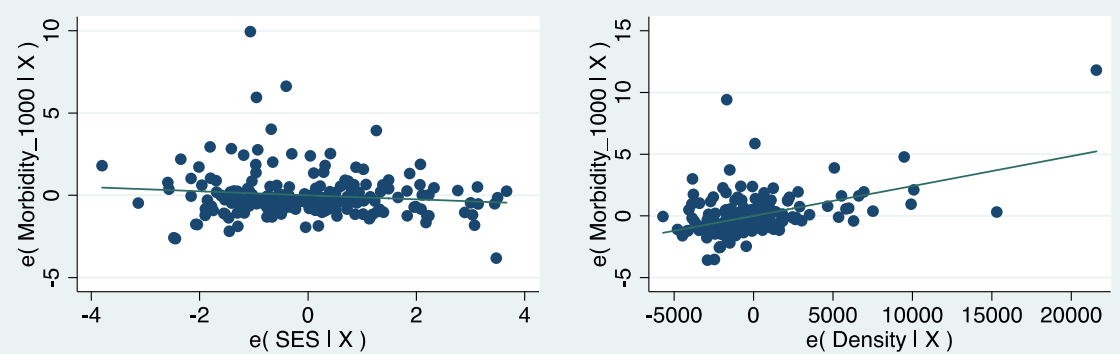

coef $=-.12256809$, (robust) $\mathrm{se}=.07270901, \mathrm{t}=-1.69$

coef $=.00024209$, (robust) se $=.00008277, t=2.92$
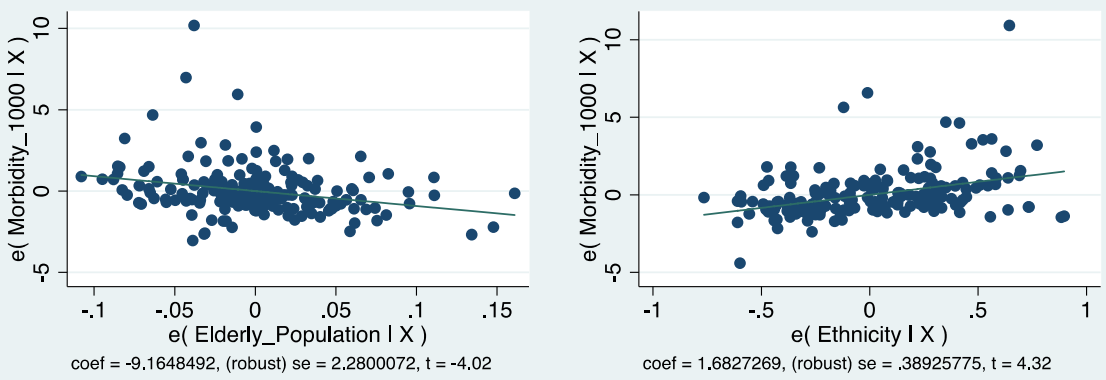

coef $=1.6827269$, (robust) se $=.38925775, t=4.32$

Fig. 4 Prediction linear regression of Morbidity in Israel (1:1000)

Figure 7 further supports Table 7 findings, showing that as internet access rises, the communities' morbidity rates decrease.

We now turn to discuss the observed trends and particularities and propose some lines of explanation.

\section{Discussion}

The current analysis revealed increased morbidity rates in dense, low SES Jewish communities with small elderly populations and low access to household Internet. This description befits first and foremost Jewish Orthodox

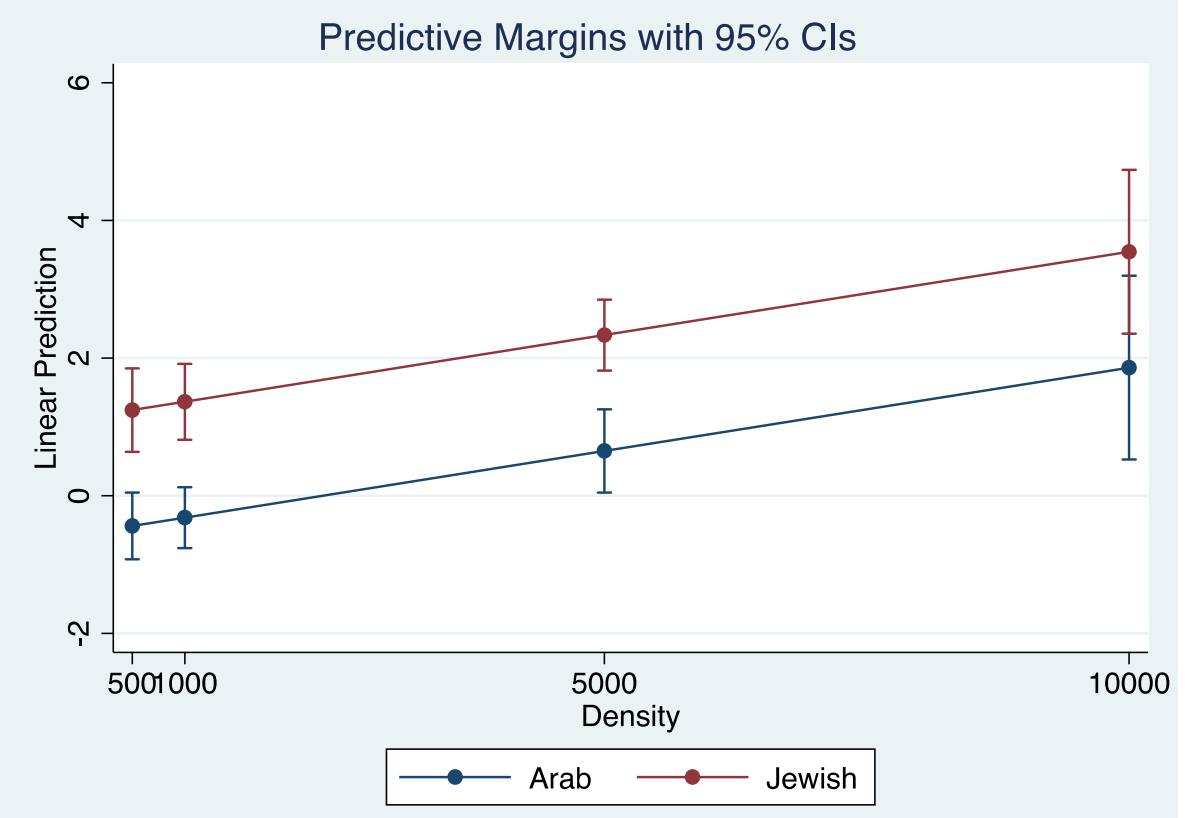

Fig. 5 Morbidity in Jewish and Arab cities by community population density 


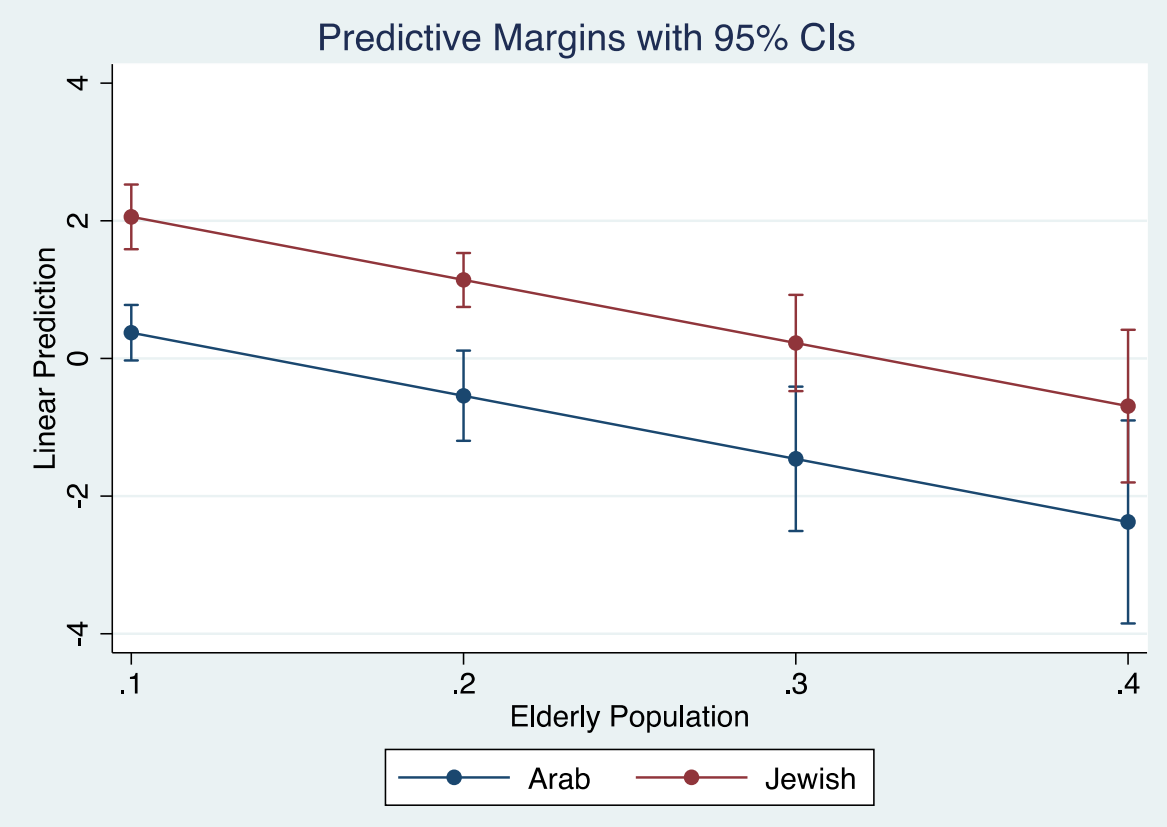

Fig. 6 Morbidity rates in Jewish and Arab communities by the number of residents aged $65+$

communities. As mentioned, these communities have indeed suffered the highest morbidity rates in Israel. More generally, population density was the only variable that emerged as statistically significant to morbidity in the entire Israeli population. In Arab communities, the lower density - 2037 vs. 3853 persons per $\mathrm{km}^{2}$ - might have contributed to the lower morbidity. The association of SES with communities' morbidity solely in Jewish cities probably reflects the relatively narrow range of SES distribution of Israel's Arab communities, which are largely clustered at the lower end of the SES scale. However, in the Jewish sector, too, SES was significant only when analyzed on its own and then, too, the association was moderate: massive differences in morbidity were observed among communities with similar $\mathrm{SES}^{6}$ and similar morbidity rates were recorded in communities far apart in their SES ranking. ${ }^{7}$

The association between morbidity and the size of a community's elderly population is probably the most peculiar finding of the present study. Israel's population is much younger than that of other industrialized countries. The main reason for the gap is the local fertility rate of 3.11 children per woman, which is nearly twice

\footnotetext{
${ }^{6}$ e.g., Beitar Illit and Segev Shalom, both rank 1, i.e., at the bottom of the SES scale, but had 4.67 vs. 0 cases per 1000 local residents respectively; Or Yehuda and Or Akiva, both ranked 5 on the SES scale but had 3.76 vs. 0.09 cases per thousand residents

${ }^{7}$ Rosh Pina and Segev Shalom had no Covid-19 cases at all, but ranked 1 and 8 respectively; Ganei Tikvah and Netivot had each 2.4 cases per thousand, but ranked 3 vs. 8 on the SES scale.
}

the OECD average of 1.7. ${ }^{8}$ In 2015, people aged $65+$ thus comprised $11 \%$ of Israel's population, representing $13 \%$ of the Jewish population and a mere $4 \%$ of Israeli Arabs. For the sake of comparison, in Japan and Italy the elderly comprise 23 and $28 \%$ of the population, respectively. ${ }^{9}$ The OECD average is $17.2 \%$. Having said that, we need to bear in mind that older people do not necessarily contract Covid-19 more often, but are rather at higher risk for complications. As such, the inverse association may not be as paradoxical as it may initially appear to be. In fact, the low proportion of elderly population might have contributed to Israel's low mortality rate. Ibe. BeyondBeyond this particular difference, the analysis revealed that when density level, SES or size of elderly population are held constant as average, the prediction of morbidity rate in the Jewish communities is 1.68 times higher than in Israel's Arab communities. This lower morbidity rate among the country's poor minority population, as compared to the wealthier majority group, counters findings from other countries. Moreover, multi-generation households, another variable associated with higher morbidity, as mentioned, are more prevalent in Israel's Arab communities than in Jewish ones [19]. How can we explain these surprising findings? What local particularities can account for this difference? We propose the following lines of explanation:

\footnotetext{
${ }^{8}$ https://data.oecd.org/pop/fertility-rates.htm

${ }^{9}$ https://data.oecd.org/pop/elderly-population.htm\#indicator-chart
} 
Table 5 Average values of the research variables by communities' nationality

\begin{tabular}{lll}
\hline Average Values & Jewish Communities & Arab Communities \\
\hline SES & 5.77 & 2.90 \\
Population Density (person $/ \mathrm{km}^{2}$ ) & 3829 & 1955 \\
\% of residents aged 65+ & 14.9 & 6.4 \\
Morbidity Rate (1:1000) & 1.64 & 0.63 \\
\hline
\end{tabular}

1. High population density and poor, large families might have rendered the lockdown harder to apply in Jewish orthodox communities. It was also harder to self-isolate in the small, congested apartments. The homecoming of children who normally study in religious boarding schools, during the epidemic, further raised the household's density.

2. For orthodox Jewish men, religious worshiping consists of 2-3 daily gatherings, conducted seven days a week. Possibly, the centrality of this routine made it harder to forego synagogue attendance, especially in the early days of the epidemic, causing delay in adherence and subsequently, excess morbidity. The lower rates of internet access in these communities might have also contributed to the delay in awareness and implementation of the lockdown instructions. Thus, possibly similarly to other places [20], the reduction in social contact was gradual in the orthodox communities, rather than immediate.

3. Numerous orthodox Jews from the U.S. arrived in Israel in the pandemic's early weeks and for a relatively long period of time were neither tested nor required to self-isolate. In retrospect, many of the incoming people were Covid-19 positive and proved to be a main source of contagion in the orthodox communities [21].

In contradistinction, Israel's Arab communities, though belonging to an underprivileged, poorer minority (e.g., [22, 23]) and often living in multi-generation households, had several protective factors:

1. Families have fewer children, especially when compared to Ultra-Orthodox Jewish families.
Additionally, Arab cities and villages are geographically peripheral and less densely populated.

2. The religious practice of the various Arab religious denominations in Israel - Muslim, Christian and Druze - does not mandate daily gathering. Indeed, Arab religious leaders were early to call for social distancing.

3. Due to various power relations and restrictions that tacitly operate in Israel's labor market, Arab citizens of Israel, are relatively well represented (though still underrepresented) among the country's health professionals [24]. Many Arab families thus have a relative who is a nurse, doctor, or pharmacist. These health professionals served, at the outbreak of the epidemic, as educators who spearheaded the new health behavior standards.

4. Having lived as a minority group that is continuously identified as an enemy, Israel's Arab citizens self-mobilized in collective effort to reduce local contagion. To this end, activists translated into Arabic information material, civil society organizations collaborated and set isolation enabling routines, like extensive collection of donations and distribution of food by volunteers. Probably the most radical practice in this respect was the unprecedented collaboration with the state's security bodies, which, for the first time in the country's history, worked together for a common goal [25].

5. Being segregated and often excluded, both national and international ties of Israeli Arabs are not as tight as those of some Jewish orthodox communities, which are closely connected to U.S. Jewish communities. In fact, most incoming traffic to Israel's Arab communities consisted of local youths studying in Arab or East European countries

Table 6 Linear regression model predicting community morbidity rates in Israel

\begin{tabular}{|c|c|c|c|c|}
\hline \multirow[t]{2}{*}{ Variables } & \multicolumn{2}{|c|}{ Non Jewish communities } & \multicolumn{2}{|c|}{ Jewish communities } \\
\hline & Model 1 & Model 2 & Model 1 & Model 2 \\
\hline SES & $-0.081(0.13)$ & $-0.046(0.17)$ & $-0.373^{*}(0.09)$ & $-0.136(0.07)$ \\
\hline Population Density & & $0.0002^{*}(0.00)$ & & $0.0002^{*}(0.00)$ \\
\hline Persons aged 65+ & & $-5.57(5.06)$ & & $-9.51^{*}(2.44)$ \\
\hline$R^{2}$ & $0.78 \%$ & $10.15 \%$ & $14.96 \%$ & $37.46 \%$ \\
\hline $\mathrm{N}$ & 85 & 71 & 173 & 126 \\
\hline
\end{tabular}


Table 7 Linear regression for the prediction of morbidity rate in Israel by household internet access

\begin{tabular}{|c|c|c|c|c|}
\hline \multirow[t]{2}{*}{ Variables } & \multicolumn{2}{|c|}{ Non Jewish communities } & \multicolumn{2}{|c|}{ Jewish communities } \\
\hline & Model 1 & Model 2 & Model 1 & Model 2 \\
\hline Households with computer and Internet access (\%) & $-0.025(0.01)$ & $-0.019(0.01)$ & $-0.034^{*}(0.01)$ & $-0.008(0.01)$ \\
\hline Population density & & $0.0001^{*}(0.00)$ & & $0.0002^{*}(0.00)$ \\
\hline Population aged 65+ (\%) & & $-1.54(4.03)$ & & $-9.94^{*}(2.39)$ \\
\hline$R^{2}$ & $11.94 \%$ & $16.0 \%$ & $13.48 \%$ & $43.0 \%$ \\
\hline $\mathrm{N}$ & 65 & 65 & 120 & 120 \\
\hline
\end{tabular}

that had relatively low Covid-19 morbidity at the time.

6. More broadly, the sharp spatial segregation between Arab and Jewish communities in Israel, also means, high ethnic density. As shown elsewhere, this structural feature often coincides with disadvantages like lower access to health care [26] and compromised health status [27], but also with improved mental [28] and physical health [29] and fewer encounters with surrounding racism [30]. Apparently, under the extreme circumstances of the epidemic, Arab communities managed to pull together their resources and coordinate an efficient collective effort to protect themselves. The fear of being stigmatized and blamed for spreading the disease, might have been another motivating factor to the implementation of strict self-discipline [25].

As of May 20, 2020, there were a total of 1040 confirmed Covid-19 cases and five deaths in Arab communities in Israel, since the outbreak of the epidemic [25].

To sum up, Arab communities in Israel were relatively less affected by the Covid-19 epidemic than Jewish communities, despite their relative poverty, minority status and prevalent multi-generational households. Lower population density and smaller families, alongside highly efficient community self-organization and collaboration with state bodies resulted in exceptionally low morbidity and mortality rates. In contradistinction, high morbidity was observed in Israel's poor, crowded Orthodox communities, especially ones with very small elderly populations.

The observed trends and differences may possibly offer an insight about potential state measures and the protection and inclusion that they have offered to marginalized communities in the context of pandemics. A comparison with morbidity patterns during Israel's second wave of Covid-19 morbidity may reveal how different containment measures have affected the health and lives of various subpopulations across the social ladder.

\section{Research limitations}

The first limitation of the current study is the focus on confirmed cases. As noted, this figure closely depends on the prevalence of testing. Moreover, assessments of the proportion of asymptomatic ill people vary widely

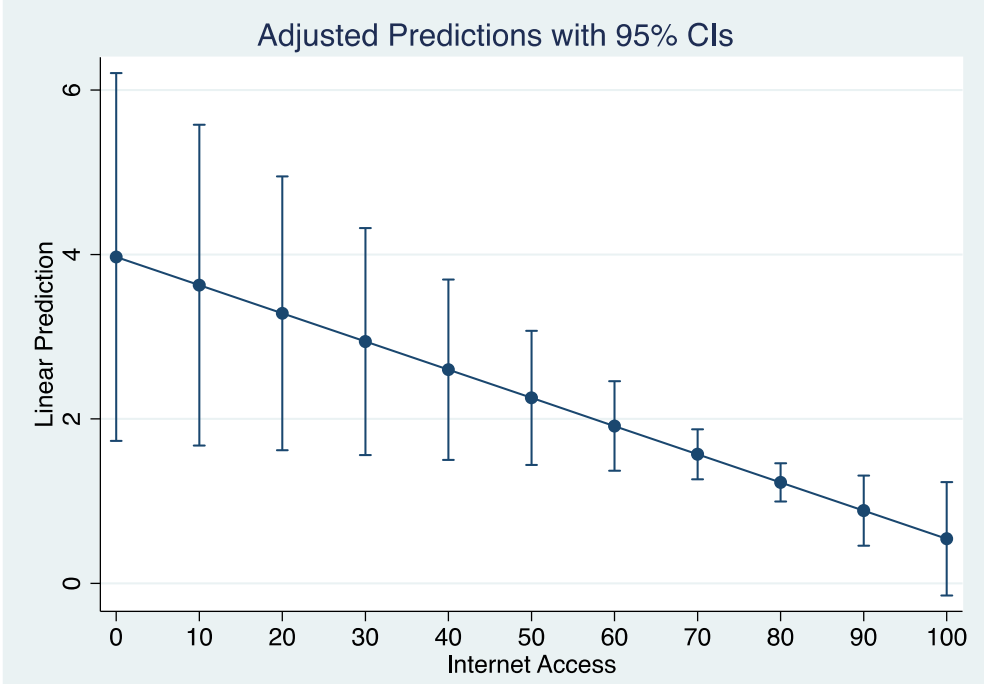

Fig. 7 Morbidity in the Jewish sector by community rate of home Internet access 
from eight to $54 \%$ (e.g., [31]). Additionally, we do not have at our disposal precise data regarding testing in the earlier days of the epidemic, let alone its distribution by communities. Another limitation emerges from the focus solely on the four scrutinized variables. Therefore potentially relevant variables, like education, religiosity, economic disparity have not been addressed. Additionally, since the analysis has been carried out, in June 2020, Israel has been suffering a much greater wave of morbidity. Not only the morbidity rates and spread pattern but also the related policies have changed dramatically. The present analysis thus brackets in only part of the epidemic in Israel. Subsequent comparative analyses that will look into the two waves will be instructive for a more nuanced understanding of the ties between morbidity, policy and social structure, namely, show how various subpopulations are affected by particular policy measures rather than others.

\section{Declarations}

The article is a secondary analysis of published data and as such did not entail any interaction with participants and ethics approval.

As the article did not entail any interaction with participants, consent was irrelevant.

Sources of data are specified in the manuscript.

The authors had no competing interests.

The submitted analysis has not been funded.

\section{Authors' contributions}

Both authors have developed the paper's framework. Daphna BirenbnaumCarmeli has written the paper and Judith Chassida has conducted the statistical analysis. The author(s) read and approved the final manuscript.

\section{Competing interest}

The authors declare that they have no competing interests.

\section{Author details}

${ }^{1}$ Faculty of Social Welfare and Health Sciences, University of Haifa, Haifa, Israel. ${ }^{2}$ Department of Sociology and Anthropology, Tel Aviv University, Tel Aviv, Israel.

Received: 22 June 2020 Accepted: 25 August 2020

Published online: 09 September 2020

\section{References}

1. Stojkoski V, Utkovski Z, Jolakoski P, Tevdovski D, Kocarev L. The SocioEconomic Determinants of the Coronavirus Disease (COVID-19) Pandemic; 2020. https://doi.org/10.2139/ssrn.3576037.

2. Abdellaoui A. Regional differences in reported Covid-19 cases show genetic correlations with higher socio-economic status and better health, potentially confounding studies on the genetics of disease susceptibility (Preprint); 2020. https://doi.org/10.1101/2020.04.24.20075333. https://www. medrxiv.org/content/10.1101/2020.04.24.20075333v1.full.pdf+html.

3. Kulu H, Dorey P. Infection Rates from Covid-19 in Great Britain by Geographical Units: A Model-based Estimation from Mortality Data; 2020. https://doi.org/10.31235/osf.io/84f3e.

4. Mansoor, Sanya. 2020. Data Suggests Many New York City Neighborhoods Hardest Hit by COVID-19 Are Also Low-Income Areas, https://time.com/5815 820/data-new-york-low-income-neighborhoods-coronavirus/, retrieved May 28, 2020.

5. Gascard N, Kauffmann B, Labosse A. 26\% more deaths between early March and mid-April 2020: dense municipalities are the most affected; 2020.

6. CDC. 2020. https://www.cdc.gov/coronavirus/2019-ncov/cases-updates/ cases-in-us.html, retrieved May 28, 2020.
7. Hill K, Dorey P. The contribution of age structure to the number of deaths from Covid-19 in the UK by geographical units; 2020. https://doi.org/10. 1101/2020.04.16.20067991.

8. Esteve A, Permanyer I, Boertien D, Vaupel JW. National age and coresidence patterns shape covid-19 vulnerability; 2020. https://doi.org/10. 1101/2020.05.13.20100289.

9. Barr, Caelainn, Niko Kommenda, Niamh Mclntyre and Antonio Voce. 2020. Ethnic minorities dying of Covid-19 at higher rate, analysis shows The Guardian, 1 May 2020, https:/www.theguardian.com/world/2020/apr/22/racialinequality-in-britain-found-a-risk-factor-for-covid-19, retrieved May 28, 2020

10. APM Research Lab. 2020. The Color of Coronavirus: Covid-19 Deaths by Race and Ethnicity in the U.S., JULY 22, 2020, Retrieved August 3, 2020, https://www.apmresearchlab.org/covid/deaths-by-race.

11. CBS (Central Bureau of Statistics). 2017. Life Expectancy in Israel, 2016, retrieved August 10, 2020, https:/www.cbs.gov.il/he/mediarelease/DocLib/2 017/362/05_17_362b.pdf.

12. CBS (Central Bureau of Statistics). 2020. Population: Demography, Immigration and Absorption. February 9, 2020. Retrieved Ausgust 3, 2020. https://www.cbs. gov.l/he/publications/Pages/2020/\%D7\%A4\%D7\%A2\%D7\%95\%D7\%9C\%D7\% 95\%D7\%AA-\%D7\%95\%D7\%A4\%D7\%A8\%D7\%A1\%D7\%95\%D7\%9E\%D7\%99\% D7\%9D-\%D7\%A1\%D7\%98\%D7\%98\%D7\%99\%D7\%A1\%D7\%98\%D7\%99\%D7\% 99\%D7\%9D-\%D7\%97\%D7\%93\%D7\%A9\%D7\%99\%D7\%9D-\%D7\%91\%D7\%99\% D7\%A9\%D7\%A8\%D7\%90\%D7\%9C-\%D7\%9E\%D7\%A1-168.aspx\#\%d7\%90\%d7\% 95\%d7\%9b\%d7\%9c\%d7\%95\%d7\%a1\%d7\%99\%d7\%99\%d7\%94.

13. Waitzberg R, Davidovitch N, Leibner G, et al. Israel's response to the COVID-19 pandemic: tailoring measures for vulnerable cultural minority populations. Int J Equity Health. 2020;19:71. https://doi.org/10.1186/s12939-020-01191-7.

14. Darlington-Pollock F, Norman P. Examining ethnic inequalities in health and tenure in England: a repeated cross-sectional analysis. Health Place. 2017;46:82-90.

15. US Department of Health and Health Services 2019. Profile: Black/African Americans, https://minorityhealth.hhs.gov/omh/browse.aspx?!v|=3\&|vlid=61.

16. Chernichovsky, Dov, Bishara Bisharat, Liora Bowers, Aviv Brill, and Chen Sharony. 2017. The Health of the Arab Israeli Population Dov, Taub Center for Social Policy Studies, http://taubcenter.org.il/wp-content/files_mf/ healthofthearabisraelipopulation.pdf, retrieved June 5, 2020.

17. Cohen Y. The politics of spatial inequality in Israel. Israeli Sociol. 2015:17(1): 7-31 Retrieved August 3, 2020, from www.jstor.org/stable/26234191.

18. Myers-JDC-Brookdale. 2018. The Arab population in Israel: fact and figures 2018. Retrieved August 3, 220. https://brookdale.jdc.org.il/wp-content/ uploads/2018/03/MJB_Facts_and_Figures_on_the_Arab_Population_in_ Israel_2018-Hebrew.pdf.

19. Azaiza F, Kroitoro T. Changes in old Persons' status in Arab families, in Yitzhak brick and Ariela Lowenatein, editors, The Elderly and the Family MultiGenerational Aspects of Aging; 2010. p. 75-89.

20. Del Fava D, Emanuele JC, Perrotta D, Grow A, Rampazzo F, Gil-Clavel S, Zagheni E. The differential impact of physical distancing strategies on social contacts relevant for the spread of COVID-19; 2020. https://doi.org/10.1101/ 2020.05.15.20102657

21. Duek, A. and K. Marciano 2020. Following the oversight in ben Gurion airport: Netanyahu instructed to stop all incoming flights, Haaretz, April 11, 2020, https://www.mako.co.il/news-lifestyle/2020_q2/Article-bcf9792d94861 71026.htm, retrieved May 30, 2020.

22. Adalah - The Legal Center for Arab Minority Rights in Israel. 2011 Inequality Report: The Palestinian Arab Minority in Israel, https://www. adalah.org/uploads/oldfiles/features/misc/Inequality_Report.pdf, retrieved June 1, 2020.

23. Kasir, Nitsa and Eran Yashiv. 2015. The labour market of Israeli Arabs: key features and policy solutions, cepr.org, February 2015, https:/cepr.org/sites/ default/files/policy_insights/Policylnsight78.pdf, retrieved June 1, 2020.

24. Popper-Givon A, Keshet Y, Liberman I. Arabs in the health and welfare professions in Israel: an ethnic and gender perspective on representativeness and employment. In: National Security, vol. 19; 2015. p. 1-32.

25. Linder, R. 2020. The Corona success story: this is how the Arabs in Israel crashed the curve, Haaretz, May 20, 2020, https://www.themarker.com/ consumer/health/premium-1.8860688, retrieved May 30, 2020.

26. Caldwell JT, Ford CL, Wallace SP, Wang MC, Takahashi LM. Racial and ethnic residential segregation and access to health care in rural areas. Health Place. 2017;:43:104-12

27. Bécares L, Das-Munshi J. Ethnic density, health care seeking behaviour and expected discrimination from health services among ethnic minority people in England. Health Place. 2013;22:48-55. 
28. Bécares L, Dewey ME, Das-Munshi J. Ethnic density effects for adult mental health: systematic review and meta-analysis of international studies. Psychol Med. 2018:48(12):2054-72. https://doi.org/10.1017/S0033291717003580.

29. Stafford M, Becares L, Nazroo J. Objective and Perceived Ethnic Density and Health: Findings From a United Kingdom General Population Survey. Am J Epidemiol. 2009;170(4):484-93. https://doi.org/10.1093/aje/kwp160.

30. Bécares L, Nazroo J, Stafford M. The buffering effects of ethnic density on experienced racism and health. Health Place. 2009;15(3):700-8.

31. Haimowitz, Gal. 2020. The invisible COVID-19 patients. Weitzman Institute of Science, April 30, 2020, retrieved August 3, 2020. https://davidson.weizmann. ac.il/online/askexpert/\%D7\%94\%D7\%97\%D7\%95\%D7\%9C\%D7\%99\%D7\% 9D-\%D7\%94\%D7\%A0\%D7\%A1\%D7\%AA\%D7\%A8\%D7\%99\%D7\%9D-\%D7\% A9\%D7\%9C-\%D7\%94\%D7\%A7\%D7\%95\%D7\%A8\%D7\%95\%D7\%A0\%D7\%94.

\section{Publisher's Note}

Springer Nature remains neutral with regard to jurisdictional claims in published maps and institutional affiliations.

Ready to submit your research? Choose BMC and benefit from:

- fast, convenient online submission

- thorough peer review by experienced researchers in your field

- rapid publication on acceptance

- support for research data, including large and complex data types

- gold Open Access which fosters wider collaboration and increased citations

- maximum visibility for your research: over $100 \mathrm{M}$ website views per year

At BMC, research is always in progress.

Learn more biomedcentral.com/submissions 